\title{
VI. DİN FELSEFESİ ATÖLYE ÇALIŞMASI: AKIL VE İMAN
}

\author{
Hüseyin AYDOĞAN*
}

Sakarya Üniversitesi İlahiyat Fakültesi ile Din Felsefesi Derneği'nin ortaklaşa düzenlediği VI. Din Felsefesi Atölye Çalışması, 02-03 Mayıs 2015 tarihleri arasında Sakarya İlahiyat Fakültesi'nde yapıldı. Sıklet merkezinde "Akıl ve İman" bahsinin olduğu çalışma, dört farklı tartışmacı ve onların müzakerecilerinin sunduğu bildiriler ışı̆̆ında yol aldı. Programın akışının iki güne yayılması ve her günde iki farklı tebliğin sunulmasıyla gerek müzakerecilere, gerekse katılımcılara geniş bir soru-cevap ve tartışma imkânı sağlanmış oldu. İşbu yazıda, mezkûr atölye çalışmasında ele alınan temel felsefi meselelere dair betimleyici bir toplu bakış sunulması ve kendi sahasında senelik bir ardışıklık sağlamayı başarabilmiş din felsefesi çalıştayının konunun meraklılarına tanıtımı hedeflenmektedir.

Dört oturum halinde gerçekleşen VI. Din Felsefesi Atölye Çalışması, ilk oturumuna, Prof. Dr. Mehmet Sait Reçber'in "Akıl ve İman Üzerine Bir Çözümleme" adlı tebliği ile başladı. Doç. Dr. Nebi Mehdiyev ve Doç. Dr. Rifat Atay tarafından müzakere edilen tebliğde, akıl ve iman meselesinin, din felsefesinin müstakil bir disiplin olarak doğuşuna kaynaklık edici bir tartışma olduğu ve günümüzde de hala canlılığını korumakta olduğu belirtildi. Girişte din-felsefe düalitesinin, akıl-iman düalitesiyle benzeştirilmemesi gerektiğinin altını çizen Reçber, buna, İslam düşüncesinde her iki düalitenin geçmişinin aynı olmayışını örnek gösterdi. Ona göre İslam düşüncesinde, akıl ve iman, bir karşıtlık olarak kendisine uzun bir geçmiş bulamazken, din ve felsefe tartışması, en başından beri hararetli tartışmalara tanık olmuştur. Öte yandan Reçber'e göre akıl ve iman tartışması, Batı felsefesi geleneğinde Tetullian'a kadar uzanan bir geçmiş barındırmaktadır. Bu bağlamda düşünürün "inanıyorum, çünkü saçma" ya da "Kudüs'ün Atina'yla ne işi var" gibi ifadeleri, akıl iman karşıtlığında radikal bir fideizmi tesis etmeye yönelik hamleler olarak görülmüştür.

Tebliğinin ikinci kısmında Modern Batı Felsefesinden örneklere yer veren mübelliğ, bu dönemin baskın karakterinin, ideolojik bir akıl savunuculuğuna vardıracak bir aklı haklılaştırma eğilimi olduğundan bahsetti. Günümüz din felsefesi alanında ise akıl ve iman ilişkisinin, daha çok teistik inançların epistemik açıdan yeterli bir haklılaştırmasının sağlanmasında temayüz ettiğini öne sürdü. Ona göre, bu sahadaki ana mesele, Tanrı'nın varlığı olduğu

* Arş. Gör., Sakarya Üniversitesi, İlahiyat Fakültesi, Felsefe ve Din Bilimleri Bölümü. 
için, tartışma, Tanrı'nın varlığının lehine ve/veya aleyhine sürülen argümanların etrafında şekillenmektedir. Tebliğinin bu kısmında Reçber, Alvin Plantinga adlı filozofun üzerinde özellikle durdu. Çünkü bu filozofun geliştirmiş olduğu Reformcu yaklaşıma göre, "dini inancın rasyonelliği, bir delil veya delillendirmeyi gerekli görmemektedir."

Oturumunun ilerleyen kısımlarında tebliğci, tüm felsefi ekolleri tatmin edecek ve her birinin beklentilerini tam olarak karşılayabilecek bir akıl tanımının olmamasından ötürü tartışmaların tam bir istikrara kavuşmamasından bahsetti. Bu bağlamda "Tanrı vardır" önermesinin analitik bir önerme olup olmadığı ve dahası bu önermenin değillemesinin, Leibniz ve Descartes gibi rasyonalistler tarafından kendi içinde çelişkili bir ifade olarak görülüp mezkûr önermenin a priori bir doğru olarak kabul edilmesine değindi. Buradan hareketle kapsamlı bir mantık felsefesi çözümlemesi yapan mübelliğ, “aklın a priori gerektirimleri noktasında mantıksal doğruluk ve çıkarımların, (veya daha geniş anlamda zorunlu doğrular) rasyonel bir doğruluk iddiasında bulunmanın asgari koşullarını ifade ettiklerinden gerekli göründüğ̈̈nü" öne sürdü. Fakat, konuşmacıya göre, "bu a priori doğrular ve çözümlemeler her zaman yeterli olmadığından, bir inancın doğruluğunu temellendirmek için akıl kavramının daha geniş anlamdaki kullanımı çerçevesinde ele alınabilecek bir delillendirmenin (haklılaştırmanın) epistemik rasyonalite açısından gerekli olduğu" söylenebilir.

Reçber, akıl kavramına yönelik çözümlemelerin ardından tebliğinde, son olarak iman bahsinin çözümlemesine yer ayırarak "önermesel ve önermesel olmayan iman" anlayışları üzerinde mütalaalarda bulundu. Önermesel olmayan daha doğrusu imanın epistemik boyutunu gerekli görmeyen iman anlayışının, rasyonel değerinden söz etmenin oldukça güç olduğunu vurguladı. Bu türden iman benimsemeleri, bir doğruluğu tasdik etmekten ziyade bir güveni öne çıkarmayı amaçlamaktadır. Mübelliğ, konuşmasını, akıl ve imanın birbirini dışlayacak şekilde konumlandırılmasından ziyade, birbiriyle etkileşimde bulunarak gidimli bir düşünceye mehaz kılınması şeklindeki bir tasavvurun, insanları daha tatmin edici bir sonuca ulaştıracağının altını çizerek sonlandirdi.

VI. Din Felsefesi Atölye Çalışması'nun ilk günündeki ikinci ve son oturum, Prof. Dr. Ferit Uslu'nun "Akıl ve İman İlişkisinde Aklın Kullanımı" başl1ğını taşıyan tebliği odağında şekillendi. Müzakereleri Prof. Dr. Fehrullah Terkan ve Doç. Dr. Kemal Batak tarafından yapılan tebliğ, akıl ve iman ilişkisinin, din felsefesinin en önemli ve en temel konusu olduğunu dikkatlere sunarak başladı. Tebliğci, son zamanlarda İlahiyat Fakülteleri'ndeki felsefe ve kelam derslerinin ağırlığını sorgulayan bir bakış açısının yerleşmeye baş- 
ladığını; ve bunun aslında akıl ve iman tartışmasında hangi tarafa daha fazla önem verildiğini ispatlar nitelikte olduğunu belirtti. Ardından tebliğinde amacının iman alanında felsefi tutumun ne olması gerektiğine dair açıklamalarda bulunmak olduğunu söyleyen Uslu, beş farklı merhaleden söz etti: Ona göre iman alanındaki aklın kullanım alanları şu şekildedir: 1. Anlama, 2. Tutarlı kılma arayışı, 3. Temellendirme, 4. Sorgulama, 5. Yorumlama. Aklın, bu alanlara dair yaklaşım ve faaliyet biçimlerine göre de "fideist akıl", "kelami akıl" ve "felsefi akıl" olarak üç farklı türe ayrılabileceğini ileri süren konuşmacı, fideist akıl ifadesinin tutarlı bir tabir olduğunu; zira fideizmi tamamen akıl karşıtı bir tutum olarak görmenin doğru olmadığını açıkladı. Bu düşüncesini Martin Luther'den cümlelerle açılayan konuşmacı fideist aklın, temelde, imanın kontrolünde ve imanla aydınlanmış bir akıl olduğunu dile getirdi.

Tebliğinin ilerleyen kısmında Uslu, başlangıçta ileri sürmüş olduğu 5 aşamanın ilki, "anlama” üzerinde durdu. Konuşmacının, imani konuların ve dini metinlerin anlaşılmasını hedef alan izahında dikkat çeken noktalar olarak şunlar sıralanabilir: Anlamaya yönelik empatik yaklaşım, sempatik yaklaşım ve son olarak antipatik yaklaşım. Her bir tavrın, birbirinden farklı başlangıç noktaları olduğunu belirten konuşmacı, ilkinde, anlamak için çaba göstermenin, ikincisinde anlamaya çoktan razı oluşun ve bununla birlikte anlaşılacak objenin kusurlarını görmezden gelmeye yönelik bir eğilimin, üçüncüsünde ise söz konusu nesneyi reddetmeye ve en başından eleştirmeye yatkın bir tutumun hâkim olduğunu ortaya koydu.

İkinci aşama olan "tutarlı kılma"da ise fideist, kelami ve rasyonel aklın birbirinden farklı tavırlar geliştirdiğini belirten Uslu, üçüncü aşama olan "temellendirme" de de bu farklılığın sürdüğünü; kelami akıl ile fideist aklı birbirinden ayıran en önemli hususun da burada tebarüz ettiğini dile getirdi. Konuşmacı, dördüncü aşama olan "sorgulama"da, felsefi aklın diğerlerine nispeten daha fazla ağırlık kazandığını öne sürdü. Ona göre fideist akıl, bu aşamada, bir çifte standart tatbik etmekte; kendi inancını, sorgulamadan uzak tutmaya çalışırken başka inançlara ise her türlü sorgulamayı uygulamaktadır. Kelami akıl da, bu evrede, "doğru olan inançlarımı nasıl delillendirebilirim" ilkesiyle yola çıkarak felsefi akıldan ayrışmaktadır. Beşinci ve son aşama olan "yorumlama" merhalesinde konuşmacı şöyle bir analizde bulundu: Fideist bakış açısı iman esaslarını ve metinlerini yorumlarken sempatik bir tavır geliştirerek yanlı bir yöntem uygulamaktadır. Kelami akıl ise, kendi dini metinini sorgulamada aklı, metni tutarlı kılma ve çelişkileri giderme aracı olarak kullanmaktadır. İslam düşüncesinde Mutezile'nin Tanrı'nın adaletini esas alarak bir akide oluşturmaya çalışması, Eş'ari'lerin Tan- 
rı'nın kudret ve iradesinin sınırsızlığını esas alarak bir inançlar manzumesi oluşturması bu evre için verilebilecek bir örnektir.

Uslu, fideizmi, aklı dışlamayan, aksine onu imanın kontrolünde bir ardıl olarak kullanan ön yargılara dayalı çıkarcı saha olarak; kelami aklı ise, aklı araçsallaştırarak kullanan savunmacı bir saha olarak; felsefi aklı ise derinlikli ve hakikat arayışına uygun evrensel ve objektif bir sahanın tesis edicisi olarak hülasa ederek tebliğine son verdi.

VI. Din Felsefesi Atölye Çalışması'nın ikinci günündeki ilk oturum, Prof. Dr. Cağfer Karadaş'ın "Kelam Nokta-i Nazarından Akıl ve Iman" adlı tebliği ile başladı. Müzakeresi Doç. Dr. Muammer İskenderoğlu ve Yrd. Doç. Dr. Mehmet Bulğen tarafından yapılan tebliğ, akıl ve iman ilişkisine, İslam düşüncesi perspektifinden hareket ederek yaklaştı. İslam düşüncesinde aklın, iyi ile kötüyü temyiz/tefrik etme gücü olarak tarif edildiğinin altını çizen konuşmacı, özellikle Mutezili âlimlerden bu meyanda örnekler sundu. Karadaş, tebliğinin ilerleyen kısmında kelam düşüncesinde dört farklı akıl tarifi olduğuna dikkat çekti. Ona göre, "Mu'tezile aklı, araz kabul etmekte; Ehl-i Sünnet kelamcılarının çoğu, aklı, ruh gibi ayan yani cevher ve cisim türünden saymakta; Şâfi ve ilk Sünnî kelamcılardan Kalanisî, aklı temyiz gücü veya aleti şeklinde tarif etmekte; İmam Eş'arî, aklı, ilmin özel bir hali olarak görmekte ve umum-husus dışında ilim ile akıl arasında aslında bir fark olmadığını dile getirmektedir." Tebliğinin büyük kısmını düşünürlere ve mezheplere göre akıl tarifi ve aklın kullanımından kaynaklanan görüş farklılıklarına ayıran mübelliğ, felsefecilerin, aklı, kadim olarak gördüklerini belirtti.

Tebliğine, aklın insan vücudundaki yeri ile devam eden Karadaş'a göre, İslam düşüncesinde buna cevap olarak kalp ve beyin gösterilmiştir. Kimi düşünürler aklın yerinin her ikisi de olduğunu belirtmişler ve bilginin, insanda idrak düzeyine ulaşmasını şöyle betimlemişlerdir: "Ruhanî manalar önce ruha, oradan kalbe intikal eder, oradan beyne yükselir, son olarak da mütahayyileye işlenir (naşk) ve böylece idrak süreci tamamlanmış olur." Karadaş'a göre, Fahreddîn er-Razî de, aklın yerinin kalp olduğunu ileri sürmüştür. Ona göre, beyin kalbin yakın aletidir. Ayrıca yine Razi, Kur'an'da kalp yerine kullanılan fuâd'ın, kalbin müradifi bir kavram değil, kalbi içine alan geniş anlamda idrak merkezi olduğunu iddia etmektedir.

Karadaş, uzun tasviri açıklamaların ardından akıl ve iman ilişkisine yeniden dönerek muhtelif düşünürlerden iman tanımları örneği vererek kalbin, imanda en önemli unsur olduğunun altını çizdi. Burada önemli bir hususa vurgu yapan konuşmacı, aklın, kalbin tasdik etme ameliyesi olduğuna dair bir izahta bulundu. Bu bağlamda aklın, Kur'an-1 Kerim'de isim olarak 
değil de fiil olarak kullanılması ve el-Hac Suresinde "kalbin akletmesi"nden bahsedilmesi bu iddiaya mesned teşkil etmektedir. Konuşmacı buradan hareketle, imanın akılla değil, kalple gerçekleşmekte olduğunu ancak gerçekleşmesinin bizatihi akıl olarak tezahür ettiğini belirtti. Bu nedenle İslam öncesi, "Cahiliyye" olarak isimlendirilmiş ve Ebû Cehil'e, bu lakap verilmiştir. Dolayısıyla kelam ile felsefedeki temel fark da, Kelamciların kalp istılahına karşın felsefecilerin aklı kullanması, benzer şekilde kelamcıların ruh ıstılahına karşın felsefecilerin de nefsi tercih etmeleridir.

İnsanın henüz ne biyolojik ne de psikolojik tarafının tam olarak keşfedilememiş olduğunu söyleyen Karadaş, tebliğini, buradan hareketle, aklın tanım ve mahiyeti üzerine bir ittifakta bulunamadığı sonucuyla bitirdi.

VI. Din Felsefesi Atölye Çalışması'nın son oturumu, Doç. Dr. Aliye Çınar'ın "Paul Tillich Düşüncesinde İman-Akıl İlişkisi” başlıklı tebliği ile açıld1. Müzakereleri Doç. Dr. Abdüllatif Tüzer ve Doç. Dr. Zeynep Gemuhluoğlu tarafından yapılan bu son tebliğ, din felsefesi alanında da önemli bir yeri olan filozof Paul Tillich'deki akıl ve iman tartışması merkezinde gerçekleşti. Diğer oturumlara göre daha müstakil ve derli toplu olduğu göze çarpan konuşma, bu hususiyetini, ele aldığı tartışma konusunu bir düşünür odağında işlemiş ve o alanda sınırlı tutmaya çalışmasına medyundu. Girişte, Tillich felsefesine dair açıklayıcı bazı argümanlar sıralayan konuşmacı, iki farklı akıl tanımı yaptı: Bunlardan ilki, aklın, gerçekliği tanımak ve denetim almak için araçlar sunan bir şey olduğu; ikincisi ise aklın, insanı insan kılan şey olup ona dil, özgürlük ve yaratıcılık temin eden bir şey olduğu. Çınar, yapmış olduğu bu akıl tanımlarının ardından iman üzerinde durarak imanın, akla zıt yahut akla muhalif olmadığını, zira böyle olsaydı eğer, onu insan kılmaktan uzaklaştıracak bir eylem olmuş olacağını belirtti. Konuşmacı, buradan hareketle imanın, insanı kuşatan ve bütün yönlerini kapsayan bir eylem olduğu ve aklı dışarıda bırakmadığını dile getirdi.

Tebliğinin ilerleyen kısımlarında, insan aklının sınırlı olduğunu ve aklın vecdî olarak kendi sınırlarını aşarak sonsuza aidiyet duymaya başladığını belirten Çınar, tam bu noktada imanın, sonsuz olanın sonlu olan insanı ele geçirmesinden başka bir şey olmadığının altını çizdi. Konuşmacıya göre, Tillich felsefesinde vecd, inkâr edilen ve dışlanan akıl değil, bütünlenen ve tamamlanan bir akıldır. Tillich felsefesinin ana konularından "kutsalla karşılaşma" ve "sonsuzun ele geçirmesi" gibi kavramların açıklanmasının dağınık ve yetersiz olduğu göze çarpan tebliğde, daha sonra, felsefi faaliyet yürüten aklın etkinliğine değinildi.

Konuşmacı, Tillich'in "tecrübe" kavramıyla olan ilişkisine geçtiği bölümde, dini tecrübede aklın teorik ve pratik yanının her ikisinin de etkin olduğu 
ve buradan hareketle sadece duyguyu değil aynı zamanda bilgi ve ritüeli de ihtiva ettiğini belirtti. Çınar'ın, konuşmasında teknik akıldan farklı olduğunu vurguladığı derinlik sahibi aklın, sezgi ile birleşerek tapınma ve ritüeli ihata edebileceği noktası da kayda değer bir başka husustu. Konuşmacıya göre, söz konusu tecrübeyi yaşayan kişide, hissetme ve bilme, iç içe geçmiş halde bulunmaktadır.

Tebliğci, konuşmasının Tillich felsefesindeki aklın ne türden bir bilgi ürettiği sorusuna cevap aradığı bölümde önemli açıklamalarda bulundu: Ona göre bilme, bilen ile bilinen şeyin birleşmesinden mürekkeptir ve böyle bir bilme de özne ile nesne yekvücut olmuştur. Bu bağlamda Tillich felsefesinde vahiy, "özel ve özgün bir şekilde gizlenen bir şeyin peçesini, eşsiz ve olağan dışı bir tezahürün kaldırması" anlamına gelmektedir. Bu gizlilik hali, mister olarak adlandırılan şeydir ve kendisine, sıradan bir bilgi eylemiyle ulaşılamaz. Çoğu zaman bir misterin sıradan dille aktarılamadığını belirten konuşmacı, onu ifade edebilecek yegâne boyutun bir sessizlik olabileceği üzerinde durdu.

Konuşmasında, vecdi aklın iş başında olduğu durumlardan birinin de mucize anları olduğunu vurgulayan Çınar, mucizenin, düşünür tarafından doğal sürece doğaüstü müdahale olarak anlaşılmadığını izah etti. Vecd kavramı, nasıl, insan aklının var olan yetilerini kaybetmeksizin ileriye doğru bir hamle yapmasını betimliyorsa; mucize kavramı da, gerçekliğin olağanın dışına çıkmasını betimlemektedir. Düşünüre göre "vecd, zihnin mucizesidir; mucize ise gerçekliğin vecdidir". Çınar; tebliğini, vahyin muhtevası, aracı ve ortamına dair kapsamlı izahlarla sona erdirdi.

\section{Değerlendirme ve Sonuç}

Gerek konuşmacıları ve müzakerecileri, gerekse katılımcılara sağladığı sorucevap imkânı ile meraklısına ve alanın uzmanlarına faydalı olduğu rahatlıkla söylenebilecek VI. Din Felsefesi Atölye Çalışması, temel problematiğini iman ve akıl tartışması odağında gerçekleştirdi. Tebliğcilerin ele aldıkları meseleleri, sadece Batı felsefesi izinde değil aynı zamanda İslam düşüncesi içerisindeki muadillerini de dikkate alarak incelemesinin, oturumları şümullü bir kapsama taşıdı̆̆ı belirtilebilir. Bu bağlamda, her tebliğin, hem felsefe hem de ilahiyat ilgililerine yarar sağladığı gözlenmiştir. Aynı zamanda tarihsel bir çerçevede kalmayarak günümüz tartışmalarına da 1şık tutması ve onları gündemine taşıması, takip edenler için kaçırılmaması gereken bir fırsat, imkân ve ortam sağlamıştır.

VI. Din Felsefesi Atölye Çalışması, oturumları müteakiben, Din Felsefesi Derneği Başkanı Prof. Dr. Rahim Acar’ın tüm katılanlara değerlendirme, 
istek ve önerilerini yazılı olarak sunabileceği bir form dağıtmasıyla ve gelecek yıl VII'cisinin düzenleneceği çalışmanın ana teması, yer ve mekânı tespitiyle ilgili müzakere ve mütalaalarla sona erdi. 